\section{CORRESPONDENCE}

Inhalation fever: a proposed unifying term for febrile reactions to inhalation of noxious substances

Sir,-The comments by Rylander and Malmberg ${ }^{1}$ and Greenburg ${ }^{2}$ on our note describing inhalation fever (1992;49:40) deserve a reply.

One example of inhalation fever, organic dust toxic syndrome (ODTS), was carefully defined at an international meeting in Sweden in 1985. ${ }^{3}$ The definition requires fever, chills, and cough without chest $x$ ray film changes or serious abnormalities of pulmonary function. (Readers will note the remarkable similarity of this definition to that generally accepted for metal fume fever.) In their letter, Rylander and Malmberg correctly state that there are reactions to organic dust and other noxious substances that may cause a variety of lung diseases. Our experience with many cases of inhalation fever suggests that the febrile reaction to inhaled fumes and particulates presents a predictable clinical picture that often causes little, if any, demonstrable damage to the lung. The febrile response, by definition, is uniformly present. Therefore, it is imperative to include the word fever in the name. The value of the word fever is further supported by the fact that several of these illnesses are already called fever by the workers who are affected-for example, mill fever.

We know of no proved human histopathological correlate of inhalation fever except for the ODTS case reported by Emanuel. That very ill patient's lung was characterised by a non-specific obliterative bronchiolitis with neutrophils in the terminal bronchiole, alveoli, and interstitium. The report did not describe a process limited to the alveolus. Therefore a specific term like alveolitis seems to be unjustified given the information at hand. Short of a lung biopsy it is impossible to make the diagnosis of alveolitis with certainty, evidence from bronchoalveolar lavage notwithstanding. The use of the term alveolitis may, in fact, confuse clinicians who associate that term with allergic alveolitis (hypersensitivity pneumonitis) such as farmer's lung.
For years inhalation fever has been mistaken for allergic alveolitis. Most knowledgeable people in the field agree that allergic alveolitis is a very rare disease. We believe the reason that allergic alveolitis had high reported prevalence rates in the past was due to the fact that inhalation fever was confused with allergic alveolitis. ${ }^{5}$

We also believe that the term toxic is not particularly helpful as it too is a non-specific term. It might give the false impression that the condition has something to do with toxic gases or that the condition is caused by toxins.

In conditions caused by inhalation of contaminated mist from humidifiers the separation in the nomenclature into two conditions is already a fact-the terms humidifier fever and humidifier lung are used. ${ }^{5} \mathrm{We}$ suggest inhalation fever as an embracing term for all the febrile conditions caused by inhalation of noxious substances. To be more specific terms such as humidifier inhalation fever, metal fume inhalation fever, and so on could be used.

The concerns of Greenburg are noteworthy. He cautions us to wait for further evidence before "lumping" the many entities described in inhalation fever together. His counsel is sound. On the other hand, the clinical picture for these exposures is compellingly similar as is the outcome in virtually all the reported cases. When disorders are this similar it is usually safe to think of them in a similar fashion. Although we have no proof that the pathophysiology is the same it certainly is possible given the highly predictable way in which subjects react to substances as diverse as zinc, cadmium, silo dust, wheat, and complex polymers.

In the absence of histopathological evidence of alveolitis and the close similarity of all the various febrile illnesses appearing after inhalation of noxious substances we believe that the term inhalation fever helps rather than hinders the understanding of these illnesses. The use of hypothetical names that are unsupported by histopathology or plausible pathophysiology seems to be overreaching our current state of ignorance. We believe that inhalation fever best meets the important mandate of utility-keep it simple.

DAVID S PRATT

ANNA RASK-ANDERSEN Department of Occupational Medicine, University Hospital, S-75185 Uppsala, Sweden

1 Rylander R, Malberg $\mathrm{P}$ (letter). $\mathrm{Br} \mathcal{f}$ Ind Med 1992;49:296.

2 Greenburg $\mathrm{M}$ (letter). $\mathrm{Br} \mathcal{F}$ Ind $\mathrm{Med}$ 1992 49:455.

3 doPico GA. Health effect of organic dusts in the farm environment. Report on diseases $\mathrm{Am} \mathbf{f}$ Ind Med 1986;10:261-5.

4 Grant IW, Blyth W, Wardrop VE, Gordon RM, Pearson JC, Mair A. Prevalence of farmer's lung in Scotland: a pilot survey, $B M \mathcal{F}$ 1972;1:530-634.

5 Baur X, Behr J, Dewair M, Ehret W, Fruhmann G, Vogelmaeier C, Weiss $\mathrm{W}$, Zinkernagel V. Humidifier lung and humidifier fever, Lung 1988;166:113-24.

\title{
A case-control study of malignant and non-malignant disease among employees of a fibreglass manufacturing facility
}

Sir,-Presenting analyses of smoking and respiratory diseases among fibreglass workers in advance of the availability of exposure histories makes the case-control studdy by Chiazze et al (1992;49:326-31) impossible to interpret. Not only is the odds ratio for lung cancer potentially confounded by exposure to fibreglass (and other exposures present), there is the serious possibility of a multiplicative risk involving smoking and a mineral fibre, as has been clearly shown for asbestos and suggested for silica. ${ }^{1}$ The unusually high odds ratio observed by Chiazze et al for lung cancer and smoking (23.5) is an indication of an important non-smoking effect.

\section{FRANKLIN E MIRER ROBERT M PARK $U A W$, Solidarity House, 800 East Fefferson Ave, Detroit, Michigan 48214, USA}

1 Goldsmith DF, Guidotti TL Combined silica exposure and cigarette smoking: a likely synergistic effect. In: Goldsmith DF, Winn DM, Shy CM, eds. Silica, silicosis, and cancer. New York: Praeger, 1986; 451-9.

Authors' reply

Sir,-We obviously disagree with the assertion by Mirer and Park that presenting the result of smoking analyses makes our case-control study ${ }^{1}$ impossible to interpret.

It is the inadequacy or total omis- 